among those in the rear of civilisation. However this may be, M. Pitre de Lisle has done good service to archæology in publishing his monograph upon this peculiar form of stone implement or weapon.

\section{INTERNATIONAL BUREAU OF WEIGHTS AND MEASURES}

UNDER the authority of the Comite International, representing several countries of Europe, the United States, and South America, there has been recently published, by Gauthier-Villars of Paris, an important volume of Memoirs by Dr. Broch (Directeur du Bureau, and Drs. Pernet, René-Benoît, and Marek (Adjoints du Bureau), on the following subjects relating to the determination of units of measure and weight.

As the intensity of weight varies with geographical position and height above level of the sea, the Comite give in their first memoir tables of the ratio of the acceleration of weight at the level of the sea, for different latitudes, to its acceleration at latitude $45^{\circ}$ (Paris), to which latitude the Comité recommend that all weighings might be referred. The tables are based on the formula of Laplace, the coefficients of which are corrected by Broch in accordance with recent deductions as to the figure of the earth. In the second memoir, which relates to the tension of aqueous vapour, certain corrections of hitherto accepted results are also indicated, particularly the errors of calculation in Regnault's tables as shown by Moritz, and new tables are given for tensions at all absolute barometer heights for normal degrees from $-30^{\circ}$ to + IOI $^{\circ} \mathrm{C}$.

With reference to the fixed points of mercurial thermometers, the Comite adopted the proposition that the point $0^{\circ}$ of the Centigrade thermometer should be fixed at the pressure of $760 \mathrm{~mm}$, when determined in $45^{\circ}$ latitude, and at the mean level of the sea. Also at the Congress of Meteorologists at Rome in 1879 there was adopted the proposition of Dr. Pernet, to fix the boiling point of water, $100^{\circ} \mathrm{C}$., under the above pressure, so as to render strictly comparable the temperatures observed at different places. Degrees of temperature between these points are termed normal-degrees.

Tables are also given, by which may be calculated the weight of a litre of pure air in different latitudes and at different altitudes. In London (lat. $=5 \mathrm{I}^{\circ} 30^{\prime}$, alt. $=6.7$ metres) the weight is $1 \cdot 293^{8}$ grammes. The Comite have adopted the term litre for expressing the volume of a kilogram of pure water, instead of the term cubic-decimetre.

In a report by $\mathrm{M}$. Herr on the Austrian unit of weight (Vienna, IS70), the volume of pure water at various temperatures is stated from the means of observations by Muncke, Stampfer, Kopp, and Pierre, the maximum density of water being taken at $3.92796 \mathrm{C}$. By this formula there have been calculated, under the directions of the Comité, tables of the volume and specific weight of water from $0^{\circ}$ to $30^{\circ} \mathrm{C}$.

One of the principal works executed during I878-9 was the comparisons of the standard kilograms at Vienna, Paris, and London. An elaborate report on these comparisons is given by M. Marek, who, by improved methods and instruments, has obtained great accuracy. The probable error of his weighings is about $0^{\circ} 002 \mathrm{mgr}$. or $1-500,000,000$ th part of the whole weight. The results also show that the material of which the standards are made, 90 per cent. of platinum and ro per cent. of iridium, is of all known bodies the least affected by time or atmospheric changes.

In a paper on Fizeau's apparatus for determining the rates of expansions of bodies by heat, by means of an optical method founded on the phenomena of interference, Dr. Benoit gives the results of his own experiences with a similar apparatus. The results show the wonderful deli- cacy of Fizeau's dilatometer, as the expansions by heat of small specimens of platinum are shown in a manner incontestable to millionths of a millimetre (o 00000004 inch).

An interesting account of the establishment and objects of the Bureau is given in a preface to this volume by the Secretary to the Comité, Dr. Ad. Hirsch ; and it is hoped that the efforts made by the Comite to bring about international agreement on the scientific points above referred to will commend themselves to all engaged in accurate work.

H. J. CHANEY

\section{A MODEL PUBLIC LIBRARY}

FNGLISHMEN are fond of descanting upon the evils of too much centralisation, which they see displayed in some foreign systems of government, urging the amount of red tape rendered almost necessary, its inflexibility, and lack of adaptation to the infinitely-varying circumstances of different communities. But, on the other hand, the extravagant cost of working every undertaking by a separate organisation, especially in a community not large enough to make such undertakings great matters, must come forcibly home to many of those who are naturally selected to work upon several.

There has lately come under our notice an admirable case of a public library avoiding this waste, securing all the energy of private zeal, and at the same time increasing the working power of it by becoming, as a public library should become, the centre of all secondary education and the parent stem of many and various branches. If any of the smaller towns of England feel that a free library would not in their case stand by itself on account of small income, we commend this to their notice as a specimen of the advantages of co-operation.

Watford has a population of about 10,000, and the penny rate on last year's gross rental of $34,589 l$. brought in $144 l .2 s$. Yet this small amount has developed round it an expenditure of $700 \%$ a year, equal to five times the largest rate collected, besides a large outlay on buildings at the beginning, costing some $3000 \%$. subscribed, in addition to the gift of the land. Ten distinct sections are worked in connection with it. The accounts of each are shown in a separate balance-sheet each year, and the agenda paper, with notice of committee-meetings, shows how methodically the work of each section is carried out and overhauled.

Section A, the Library proper, contains about 7000 volumes ; a payment of three shillings a year, or fourpence a month, is required for taking books home to read; the yearly issues accordingly amount to about 12,000. The only free part of the library, the reading-room, shows a something similar use of books; it is patronised chiefly by young men in the winter time, under the arrangements of Section D. The small subscription enables the book committee to spend about $50 \%$. a year in new books; magazines and periodicals being supplied by a separate club, connected, of course, with the institution. We should be glad to see the troublesome and irksome system of guarantors dropped. Towns which have freed themselves from the labour and annoyance they entail, though containing far larger proportions of the "great unknown" than can a place of the size of Watford, have found no evil result. The subscription also, though small, seems to render it less necessary here.

Section B is the School of Science and Art, the latter division showing clearly that the public library at Watford by no means attends to the wants of the industrial classes only, for non-Government pupils may pay six guineas a year for drawing only. For the benefit of the evening classes, at which non-Government pupils pay a guinea and a half for the year's instruction, and Government students (whose income, that is, or parents' income, does not exceed $200 \%$. a year) half that, "the subjects are 
arranged to meet the requirements of artisans and those engaged in mechanical trades, and include mechanical drawing, building, construction, modelling, model drawing, outline drawing, and shading."

This section includes science teaching also, and classes were formed last year in inorganic chemistry, botany, principles of agriculture, fully illustrated by experiments ; shorthand also, a useful help to all such studies.

Section C is Entertainments, and is set going or stopped as occasion offers; of course it is expected to be a help to the general fund.

Section $D$ is the Youths' Institute, supported also by special honorary subscribers and by one penny a week paid by its members for admission to the reading-room, because without that the room was too full. Let us hope that such a very unsatisfactory statute of limitations may soon cease to be necessary. An extra rate would hardly be grudged in such a case, and it is a strong argument for Parliament authorising one.

Section $\mathrm{E}$ is a Private Subscription-room, supported by about a hundred members, who subscribe ten shillings a year each, spent in newspapers and periodicals, made available to the public after their use by the club.

Section $F$ is a School of Music, where some of the best masters obtainable in London are engaged, two of whom take the combined instruction, and four take separate instruction. Nine different classes of lessons are arranged for, again not free, but all made available to those who wish for them, at very little expense or labour to themselves. It is now supported by 160 students, and by subscriptions from the vice-presidents.

Section G is the nucleus of a Museum ; and how treasures of local interest are lost to a town for want of such a nucleus in trustworthy hands, the writer knows well ! Central museums also can easily supply duplicate treasures to such institutions in almost perpetual succession.

Section $\mathrm{H}$, the English Literature Club, meets weekly through the winter, at the library rooms, adding greatly to the care with which books are real, and, consequently, to the pleasure and information drawn from them. A very small subscription pays its, no doubt very small, expenses.

Even needlework in elementary schools, though spread about half the County of Herts, and patronised by a goodly company of influential ladies throughout the district, has its "head centre" in a committee of three gentlemen of the Watford Public Library. Fifty-four schools compete, and 1500 specimens are shown, in six classes of work, all having undergone a strict and very systematic examination.

The same association supports also a School of Cookery.

Other offshoots of the Library are the Herts Natural History Society, the Foresters' Club, Junior Foresters' Club, and the Shepherds' Club, each having its meetingplace at the library rooms.

Now among this variety of work there is probably none which is not carried on in nearly all the larger towns of England by some means. What we wish to set forth is the reasonableness of its all forming together the work of a single "committee of education," not necessarily elementary only by any means; and that a ratesupported public library should be the central institution, whose committee should set in co-ordinate motion all the parts of this local educational machine. Such a committee need not attempt to take into its hands the entire control of each separate branch, but should work all together with as little friction and loss of labour as possible, and especially should this be the case, as we have said, in our smaller towns. Very great is the economy of one institution working all together, in the matter of rooms, advertising, and printing; in one man receiving, as the librarian does at Watford, all the subscriptions and fees paid to these various societies, the 5 per cent. allowed him upon all giving him a tangible interest in increasing each, as such a central worker must have the means of doing, and in stirring all up to a friendly rivalry in welldoing. And the advantage can hardly be over-stated of the power of such on orgarisation to bring together earnest workers, who might otherwise have followed either a secluded path or one crossing that of other workers; in the one case, occurring most frequently in small communities, doing little for the advance of intelligence and information; and in the other case, to which large cities are most liable, wasting time and efforts which are often thwarted by mere local jealousies.

\section{NOTES}

IN June of the present year the freshwater jelly-fish (Limno. codium Sowerbii) reappeared in the Royal Botanical Society's Gardens, Regent's Park, though in no great numbers. At the suggestion of Mr. George Busk, F.R.S., and with the courteous assistance of Mr. W. Sowerby, a s sall number were captured and transferred to the Victuria tank in Number ro House at the Royal Gardens, Kew. Nothing was known of their fate till about a week ago, when it was observed that the whole tank was swarming with the progeny of the small colony brought from London.

THE Local Committee at York have been making laudable exertions for the accommodation of those who intend to be present at the meeting of the British Association next week. They have prepared a long list of hotels and lodgings, with prices, at the same time stating that the prices of the lodgings are higher than will be eventually charged, "as there is abundance of good accommodation at reasonable rates." They have also issued a time-table of the arrivals and departures of trains at York station from the principal towns in the kingdom, with special tables for the local lines. A map of the city has besides been prepared, showing the situation of the principal buildings, the meeting. places of the various sections, and the principal hotels, of which there are fourteen.

The Times Geneva correspondent gives some further particulars concerning Prof. Raoul Pictet's model steamer now in course of construction, with which he expects to reach a speed of forty miles an hour, and which will make a trial trip on the lake in November next. Her dimensions are-16 metres long and 3.50 metres wide. When lying at anchor she will draw 33 centimetres fore and 44 centimetres aft; at full speed I centimetre forward and 16 centimetres aft. The engine will be placed amidships, from which point to the stern the screw-shaft and the keel form an inclined plane; the bows are long, taper. ing, and wedge-shaped. Prof. Pictet reckons that his invention will lead to a great saving of fuel, inasmuch as a steamer built on his plan, after being started with say 100 horse-power, may be kept up full speed with an expenditure of force equal to thirty horses. The form of the hull, on which the maintenance of the ship's equilibrium will depend, cannot be explained without a diagram. Prof. Pictet is quite confident in the success of his invention, and his previous scientific achievements have been so remarkable that many people who cannot follow his reasoning have no hesitation in accepting his conclusions.

THE inhabitants of Havre are collecting money for raising a statue to Sauvage, who is considered in France as having applied the screw to the propelling of steamers.

A TELEGRAPHIC experiment of a singular description was tried last week at the Trocadéro. It consists merely in the reading of large silvered zinc letters, a square metre in size, fixed on a blackened board, by refracting telescopes. This method has succeeded very well from the Trocadéro to the Panthéon, a distance of about three miles. The inventor, an 